\title{
Effect of high vitamin A or tocopherol intake on hepatic lipid metabolism and intestinal absorption and secretion of lipids and bile acids in the chick
}

\author{
BY DAVID SKLAN \\ Faculty of Agriculture, The Hebrew University of Jerusalem, PO Box 12, \\ Rehovot 76-100, Israel
}

(Received 17 May 1982 - Accepted 15 April 1983)

\begin{abstract}
1. The effect of high dietary vitamin $\mathbf{A}$ or tocopherol, or both, on lipid absorption and secretion in the gastrointestinal tract and on serum and hepatic lipids was determined in the chick.

2. High dietary vitamin $A$ increased secretion of cholesterol, bile acids, phospholipids and fatty acids to the duodenum, and tocopherol enhanced cholesterol and bile acid secretion to the duodenum. No differences in over-all absorption were observed.

3. Serum cholesterol was depressed by vitamin $A$ and hepatic lipids were enhanced, except phosphatidyl choline which was depressed. Tocopherol increased hepatic triglycerides and cholesterol.

4. In vitro fatty acid synthesis from lactate by liver homogenates was enhanced by vitamin E and cholesterogenesis enhanced by both vitamin $\mathrm{A}$ and tocopherol. $\Delta^{9}$ Desaturation was also enhanced by vitamin $\mathrm{E}$.

5. It is concluded that both vitamin $A$ and tocopherol affect the hepatic synthesis and catabolism of cholesterol and that vitamin $\mathrm{E}$ also influences fatty acid metabolism.
\end{abstract}

High intakes of vitamin A affect both serum and hepatic lipid concentrations. March \& Biely (1963) reported that serum cholesterol was depressed in the chick by increasing vitamin A intake and attributed this to an absorption effect; a similar effect has been observed in the rat (Bring et al. 1965; Lakshmanan et al. 1969; Prodouz \& Naveri, 1975). Serum triglycerides (TG) have been reported by some to be increased by high vitamin A intakes (Solomon \& Erdman, 1980; Setty \& Misra, 1981) and by others to be decreased (Bring $e t$ al. 1965; Harrill et al. 1965). Hepatic TG were enhanced by high vitamin A intakes with the eventual production of fatty liver in hypervitaminosis A (Singh et al. 1969; Mallia et al. 1975; Singh \& Singh, 1978). In addition, total hepatic phospholipids (PL) were increased although phosphatidyl choline (PC) was depressed in the rat (Ram \& Misra, 1978). Phospholipid synthesis through the cytidine diphosphate - choline ethanolamine pathway was depressed and PC fatty acid composition changed, with, in particular, a reduction in arachidonic acid in rat heart on feeding high levels of vitamin A (Setty \& Misra, 1981).

Singh \& Singh (1978) and Setty \& Misra (1975) indicated that fatty acid synthesis was enhanced by vitamin $A$ in the rat but that fatty acid transport from the liver was impaired, resulting in accumulation of fatty acids.

High intakes of tocopherol have also been shown to enhance hepatic cholesterol and TG (Yang \& Desai, 1977; Porta et al. 1981) and depress serum cholesterol (Prodouz \& Naveri, 1975; Porta et al. 1980). In addition, hepatic cholesterol $7 \alpha$-hydroxylase activity was enhanced by tocopherol (Kritchevsky et al. 1980). This would presumably increase the formation of bile acids from cholesterol.

The object of the present study was to determine the effects of, and interaction between, vitamin $A$ and tocopherol on the enterohepatic circulation of cholesterol, bile acids and fatty acids, and to relate this to the changes in hepatic and serum lipid levels in the chick. 


\section{EXPERIMENTAL}

[U-14 C]lactate and $\left[1-{ }^{14} \mathrm{C}\right]$ stearic acid were obtained from Amersham International, Amersham, Bucks.

New Hampshire $\times$ Leghorn male chicks were given diets containing $(\mathrm{g} / \mathrm{kg}): 608$ sorghum, 323 soya-bean meal, 30 soya-bean oil (Sklan \& Donoghue, 1982) to which D- $\alpha$-tocopheryl acetate and retinyl acetate were added as follows: Control diet, $10 \mathrm{mg}$ tocopheryl acetate $/ \mathrm{kg}, 850 \mu \mathrm{g}$ retinyl acetate $/ \mathrm{kg}$; diet E, $200 \mathrm{mg}$ tocopheryl acetate $/ \mathrm{kg}, 850 \mu \mathrm{g}$ retinyl acetate $/ \mathrm{kg}$; diet A, $10 \mathrm{mg}$ tocopheryl acetate $/ \mathrm{kg}, 350000 \mu \mathrm{g}$ retinyl acetate $/ \mathrm{kg} ; \operatorname{diet} \mathrm{A}+\mathrm{E}$, $200 \mathrm{mg}$ tocopheryl acetate $/ \mathrm{kg}, 350000 \mu \mathrm{g}$ retinyl acetate $/ \mathrm{kg}$. Chicks were given these diets from hatching, water was supplied ad lib.

\section{Expt 1}

After $21 \mathrm{~d}$ on the diets previously described the chicks were transferred to the same diets to which $50 \mu \mathrm{Ci}{ }^{141} \mathrm{Cerium} / \mathrm{kg}$ had been added as a non-absorbed reference substance. After $4 \mathrm{~d}$ on this diet, animals were bled with a heparinized syringe and killed with an overdose of sodium pentothal. Contents of five intestinal segments were removed as previously described (Sklan et al. 1975a).

Intestinal contents were homogenized with a high-speed homogenizer and a portion taken for ${ }^{141} \mathrm{Ce}$ determination by $\gamma$-scintillation. Additional portions were taken for bile acid determination (Singer \& Fitschen, 1961) and for extraction and fatty acid, phospholipid and cholesterol determinations as previously described (Sklan et al. 1975a). Hepatic and plasma lipids were extracted with chloroform-methanol (Folch et al. 1957), separated by thin-layer chromatography after addition of heptadecanoic acid, and triheptadecanoylglycerol and diheptadecanoyl phosphatidyl choline used as internal standards. To cholesterol esters heptadecanoic acid was added before methylation and gas-liquid chromatography (Sklan et al. 1975b). Phospholipids were separated by thin-layer chromatography using silica gel $G$ and chloroform-methanol-acetic acid-water $(65: 25: 4: 1$, by vol.) as the developing solvent.

\section{Expt 2}

Chicks that received the experimental diets for $24 \mathrm{~d}$ were killed with an intracardiac overdose of sodium pentothal. Livers were removed and homogenized with $0.25 \mathrm{M}$-sucrose $(1: 3, \mathrm{w} / \mathrm{v})$ and synthesis of fatty acids and cholesterol from $\left[{ }^{14} \mathrm{C}\right]$ lactate determined as described by Riesenfeld et al. (1981). An additional portion of the homogenate was taken for $\Delta^{9}$ desaturase determination as described by Wahle (1974).

\section{Calculations}

When a non-absorbed reference substance is fed until a steady-state with regard to input-output is attained, the ratio between any dietary component and the reference substance can be used to calculate net changes between successive segments. A decrease in the ratio is defined as disappearance and, in the absence of extensive intraluminal metabolism, can be regarded as absorption. An increase in the ratio will represent net secretion. Multiplying the ratio of any component to the reference substance by the daily intake of the reference substance will give the daily flow of that component at that point.

Two-factor analysis of variance was by standard methods.

\section{RESULTS}

Vitamin A and tocopherol concentrations in plasma and liver, after $24 \mathrm{~d}$ on the experimental diets, are shown in Table 1 (see also Sklan, 1983). Plasma and liver vitamin A levels were 
Table 1. Plasma and liver concentrations of vitamin $A$ and tocopherol in chicks after $24 d$ on the experimental diets*

(Mean values and standard deviations of logs of values for six chicks. Two factor analysis of variance was used to test for significance of vitamin $A(A)$, tocopherol $(E)$ or the interaction $(A+E)$ )

\begin{tabular}{|c|c|c|c|c|c|c|c|c|c|}
\hline \multirow[t]{2}{*}{ Diet... } & \multicolumn{2}{|c|}{ Control } & \multicolumn{2}{|c|}{ E } & \multicolumn{2}{|c|}{ A } & \multicolumn{2}{|c|}{$A+E$} & \multirow[b]{2}{*}{$P<0.05$} \\
\hline & Mean & SD & Mean & SD & Mean & SD & Mean & SD & \\
\hline \multicolumn{10}{|l|}{ Plasma } \\
\hline $\begin{array}{c}\text { Vitamin } A \dagger \\
(\log \mu \mathrm{g} / \mathrm{l})\end{array}$ & $2 \cdot 47$ & 0.03 & $2 \cdot 39$ & 0.04 & $2 \cdot 83$ & $0 \cdot 03$ & $2 \cdot 84$ & 0.04 & $\mathrm{~A}, \mathrm{E}, \mathrm{A}+\mathrm{E}$ \\
\hline Tocopherol $(\log \mu \mathrm{g} / 1)$ & $3 \cdot 83$ & 0.07 & $4 \cdot 83$ & 0.03 & $3 \cdot 83$ & 0.09 & $4 \cdot 17$ & 0.05 & $\mathrm{~A}, \mathrm{E}, \mathrm{A}+\mathrm{E}$ \\
\hline \multicolumn{10}{|l|}{ Liver } \\
\hline $\begin{array}{l}\text { Vitamin A } \dagger \\
(\log \mu \mathrm{g} / \mathrm{g})\end{array}$ & 1.69 & 0.02 & 1.75 & 0.04 & $3 \cdot 41$ & 0.05 & $3 \cdot 62$ & 0.03 & $A, E, A+E$ \\
\hline Tocopherol $(\log \mu \mathrm{g} / \mathrm{g})$ & $1 \cdot 13$ & $0 \cdot 07$ & 1.89 & 0.05 & 0.73 & 0.07 & 1.49 & 0.06 & A, E \\
\hline
\end{tabular}

* For details of diets, see p. $\mathbf{4 1 0 .}$

$\dagger$ Retinol equivalents.

affected by dietary vitamin $\mathrm{A}$ and by tocopherol; an interaction between these factors was observed. High dietary tocopherol enhanced plasma and hepatic concentrations and dietary vitamin A decreased both plasma and hepatic tocopherol concentrations; in $\mathrm{A}+\mathrm{E}$ chicks tocopherol levels were increased to levels less than in E chicks. The interaction, however, was not significant.

Values for fatty acid: ${ }^{141} \mathrm{Ce}$ along the gastrointestinal tract are shown in Fig. 1 together with those of phospholipids, bile acids and cholesterol. Chicks showed secretion of fatty acids into the duodenum and this secretion was highest in A-treated chicks. Phospholipid secretion paralleled the fatty acid secretion with A-treated chicks showing the highest secretion. Cholesterol secretion to the duodenum was also higher in A-fed chicks than with other treatments and E-fed chicks also showed more secretion than the controls $(P<0.05)$. Bile acids showed a similar pattern, with all treatments showing more secretion than controls. In A-fed chicks, secretion was again significantly higher than $\mathrm{E}$ - and $\mathrm{A}+\mathrm{E}$-treated chicks (Fig. 1). Little difference was apparent in these measurements between dietary treatments by the lower jejunum, and no significant differences in over-all absorption were observed. Calculations of the daily flows along the gastrointestinal tract are shown in Table 2. A-treated chicks showed highest fluxes of fatty acids, phospholipids, bile acids and cholesterol, with A + E-fed chicks generally intermediate between A-fed and controls; E-fed chicks showed enhanced bile acid and cholesterol fluxes. Vitamin A effects and the $\mathrm{A}+\mathrm{E}$ interaction were significant but tocopherol effects were not. Ileal fluxes were not significantly different for fatty acids or cholesterol although all treated chicks showed slightly decreased bile acid flows.

Plasma total fatty acids were raised in E-fed chicks whereas A-fed chicks showed lower plasma cholesterol and E-fed chicks higher cholesterol than control chicks (Table 3). Concentrations of hepatic lipid fractions are shown in Fig. 2. All treatments elevated total fatty acids and total cholesterol. The increase in total fatty acids was paralleled by an increase in TG as well as an increase in PL in A- and A + E-fed chicks. PC, however, was slightly depressed in A-treated chicks. Cholesterol esters increased in all treatments. The fatty acid profiles of different lipid fractions are shown in Table 4. Total fatty acids (not shown) showed that A-fed chicks had more $18: 1$ fatty acids than controls $(P<0.01)$ and triglycerides reflect this change with inverse fatty acid changes occurring in 18:2. PL 18:0, 


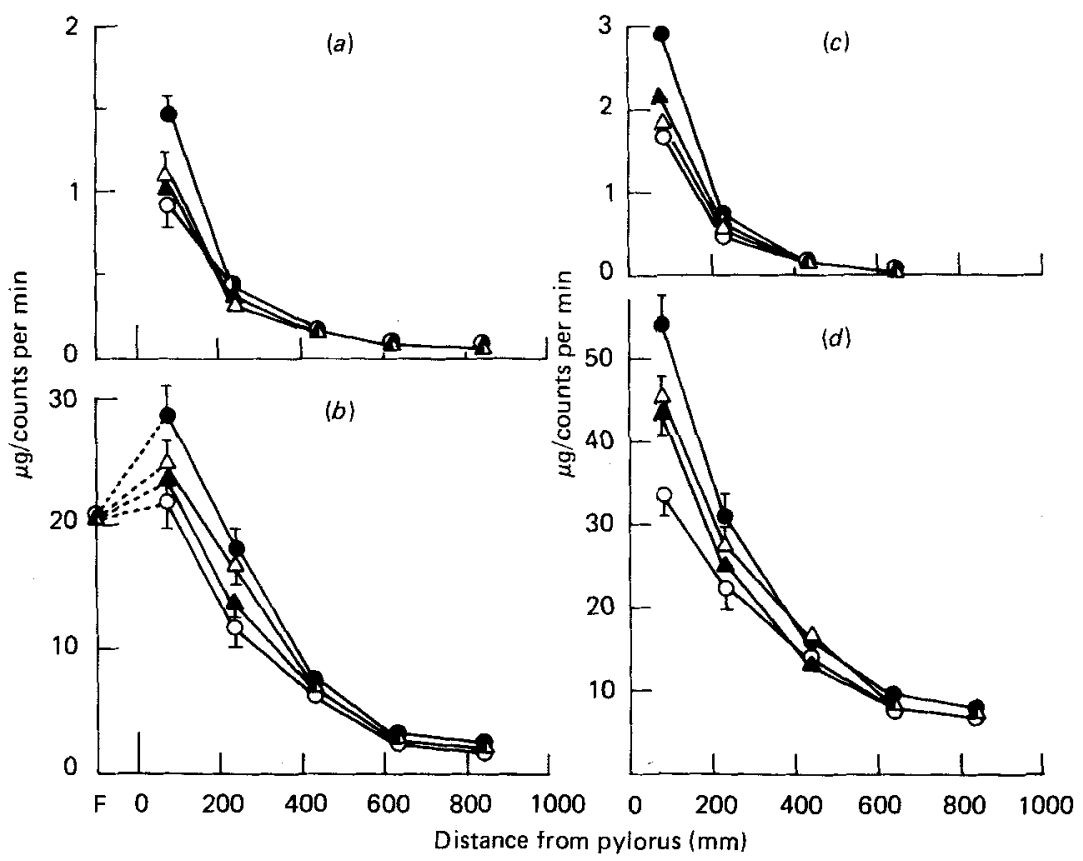

Fig. 1. Values for $(a)$ cholesterol: ${ }^{141} \mathrm{Cerium},(b)$ fatty acids: ${ }^{141} \mathrm{Ce},(c)$ phospholipids: ${ }^{141} \mathrm{Ce}$ and $(d)$ bile acids: ${ }^{14} \mathrm{Ce}$ with distance from the pylorus in chicks given the control diet $(O)$, high vitamin $\mathrm{A}(\mathrm{O})$, tocopherol $(\Delta)$ or high vitamin $A$ and tocopherol $(\Delta)$ diets (for details of diets, see p. 410). The results are means and SD of results obtained for five chicks. The various segments correspond to 0-190 $\mathrm{mm}$ duodenum, $190-530 \mathrm{~mm}$ jejunum and $540-850 \mathrm{~mm}$ ileum. Values for coefficient of variation did not exceed $16 \%$ at any point.

Table 2. Daily flows of fatty acids, bile acids and cholesterol through the gastrointestinal tract of chicks given the experimental diets*

(Mean values and standard deviations for five chicks. Two factor analysis of variance was used to determine the significance of the effect of vitamin $A(A)$, tocopherol (E) and the interaction $(A+E)$ )

\begin{tabular}{|c|c|c|c|c|c|c|c|c|c|}
\hline \multirow[t]{2}{*}{ Diet... } & \multicolumn{2}{|c|}{ Control } & \multicolumn{2}{|c|}{$\mathbf{E}$} & \multicolumn{2}{|c|}{ A } & \multicolumn{2}{|c|}{$A+E$} & \multirow[b]{2}{*}{$P<0.05$} \\
\hline & Mean & SD & Mean & SD & Mean & SD & Mean & SD & \\
\hline \multicolumn{10}{|l|}{ Duodenal flows } \\
\hline Bile acids & $306 \cdot 1$ & $43 \cdot 8$ & $406 \cdot 4$ & $33 \cdot 4$ & $523 \cdot 4$ & $41 \cdot 2$ & $442 \cdot 2$ & $31 \cdot 6$ & $A, A+E$ \\
\hline Cholesterol & $10 \cdot 5$ & $0 \cdot 9$ & $12 \cdot 9$ & 1.0 & 14.9 & 1.2 & 11.4 & 1.3 & $A, A+E$ \\
\hline Fatty acids & $795 \cdot 2$ & $83 \cdot 4$ & $873 \cdot 4$ & 81.8 & $1001 \cdot 3$ & $21 \cdot 2$ & $872 \cdot 0$ & $60 \cdot 1$ & $\mathrm{~A}, \mathrm{~A}+\mathrm{E}$ \\
\hline Phospholipids & $63 \cdot 0$ & $6 \cdot 3$ & 63.5 & $4 \cdot 1$ & $105 \cdot 6$ & $14 \cdot 3$ & 78.4 & $6 \cdot 4$ & $\mathrm{~A}, \mathrm{E}, \mathrm{A}+\mathrm{E}$ \\
\hline \multicolumn{10}{|l|}{ Ileal flows } \\
\hline Bile acids & $60 \cdot 8$ & $4 \cdot 1$ & 55.8 & 4.8 & $53 \cdot 4$ & $5 \cdot 1$ & $46 \cdot 5$ & $4 \cdot 3$ & $A+E$ \\
\hline Cholesterol & $2 \cdot 8$ & 0.7 & $2 \cdot 6$ & 0.4 & $2 \cdot 9$ & 0.2 & $2 \cdot 8$ & 0.3 & \\
\hline Fatty acids & $82 \cdot 2$ & 5.9 & $77 \cdot 2$ & $6 \cdot 3$ & $84 \cdot 5$ & $6 \cdot 1$ & $81 \cdot 3$ & 7.4 & \\
\hline
\end{tabular}

* For details of diets, see p. 410. 
Table 3. Serum cholesterol and total fatty acids in chicks given the experimental diets*

(Mean values and standard deviations for six chicks. Values for treatments were tested by two factor analysis of variance for the significance of vitamin $A(A)$, tocopherol $(E)$ and the interaction $(A+E)$ )

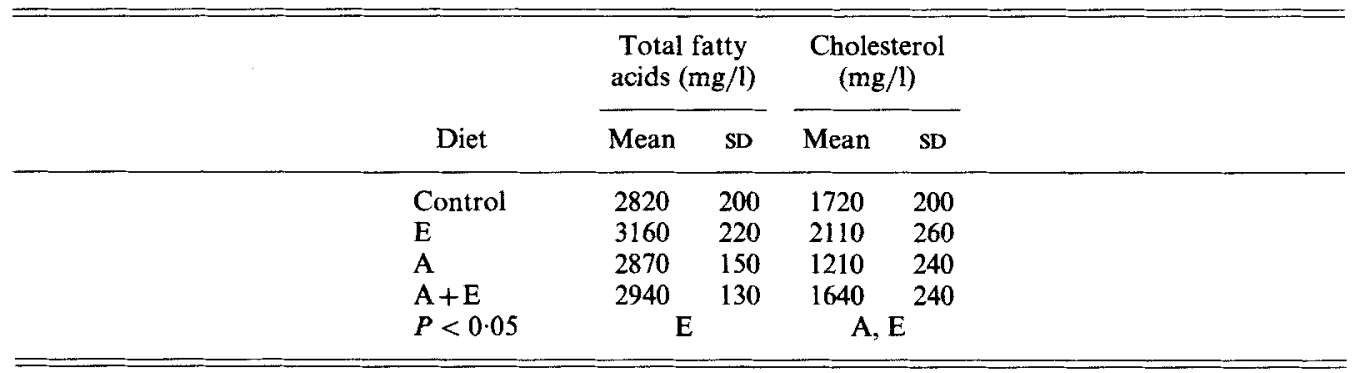

* For details of diets, see p. 410.
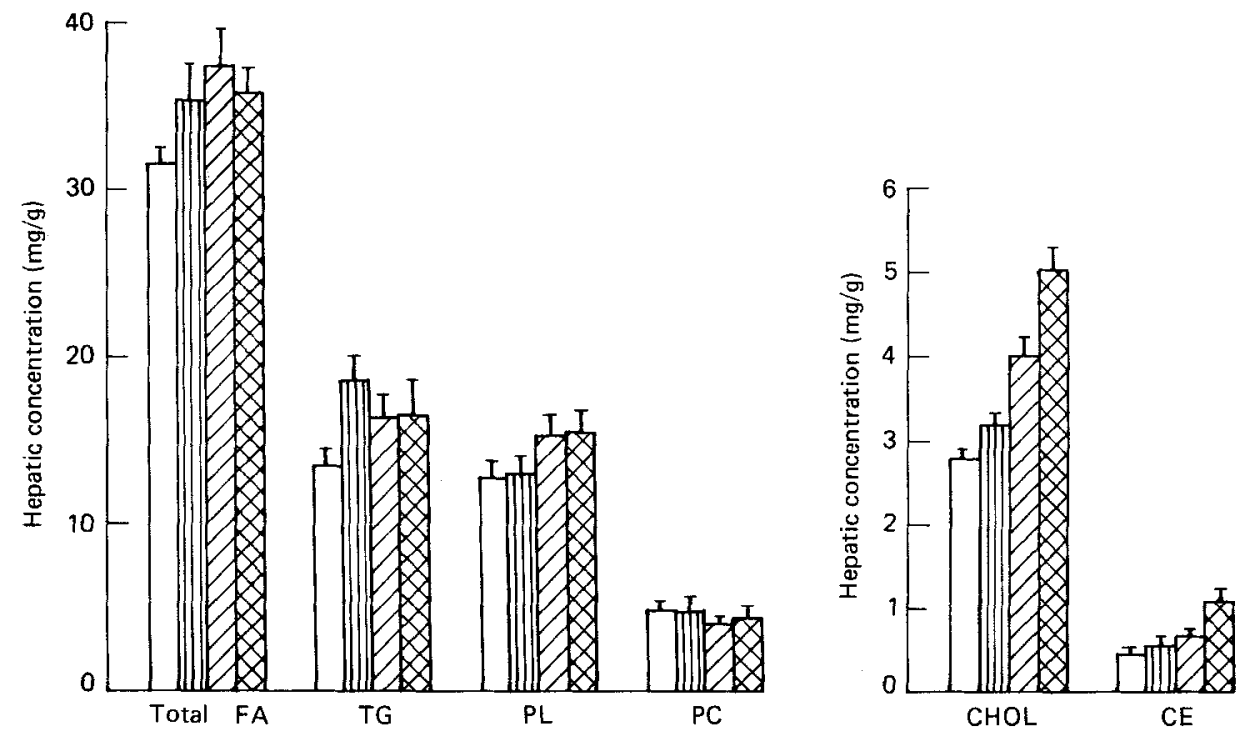

Fig. 2. Effect of the experimental diets on hepatic total fatty acids (total FA), triglycerides (TG), phospholipids (PL), phosphatidyl choline (PC), total cholesterol (CHOL) and cholesteryl esters (CE) in chicks given control ( $\square$ ), tocopherol (四), high vitamin A (国) or high vitamin A and tocopherol (ख) diets. Results are means and sD for six chicks.

18:1 and 18:2 were affected by $A$ and the $A+E$ interaction was significant. 20:4 Levels were affected by $E$ and the interaction was again significant. Cholesterol ester fatty acids were influenced mainly by $A$, with an $A+E$ interaction apparent for 16:0,18:0,18:1 and 20:4. More 18:0 and less 20:4 were found in the A- and A+E-treated chicks. In vitro incubations of liver homogenates showed that cholesterol synthesis from lactate was enhanced in all treatments and fatty acid synthesis was depressed by $E$ with a significant $\mathrm{A}+\mathrm{E}$ interaction. $\Delta^{9}$ Desaturation was depressed in $\mathrm{E}$-treated chicks and an $\mathrm{A}+\mathrm{E}$ interaction was significant (Table 5). 
Table 4. Fatty acid composition of lipid fractions from liver of chicks given the experimental diets*

(Mean values and standard deviations for five chicks. Fatty acids comprising less than $1 \%$ of total were excluded from the calculations. Two-factor analysis of variance was used to determine significance of vitamin $A(A)$, tocopherol $(E)$ and the interaction $(A+E)$. Fatty acids are designated by the number of $\mathrm{C}$ atoms: number of double bonds)

\begin{tabular}{|c|c|c|c|c|c|c|c|c|c|c|c|}
\hline \multirow[b]{3}{*}{ Lipid } & \multirow{3}{*}{$\begin{array}{c}\text { Experimental } \\
\text { treatment }\end{array}$} & \multicolumn{10}{|c|}{ Fatty acid } \\
\hline & & \multicolumn{2}{|c|}{$16: 0$} & \multicolumn{2}{|c|}{$18: 0$} & \multicolumn{2}{|c|}{$18: 1$} & \multicolumn{2}{|c|}{$18: 2$} & \multicolumn{2}{|c|}{$20: 4$} \\
\hline & & Mean & SD & Mean & SD & Mean & SD & Mean & SD & Mean & SD \\
\hline Total phospholipids & $\begin{array}{l}\text { Control } \\
+\mathrm{E} \\
+\mathrm{A} \\
\mathrm{A}+\mathrm{E} \\
P<0.05\end{array}$ & $\begin{array}{l}23 \cdot 6 \\
23 \cdot 8 \\
23 \cdot 3 \\
22 \cdot 8\end{array}$ & $\begin{array}{l}1 \cdot 1 \\
1 \cdot 2 \\
2 \cdot 1 \\
1 \cdot 2\end{array}$ & $\begin{array}{c}34 \cdot 3 \\
34 \cdot 0 \\
32 \cdot 0 \\
31 \cdot 9 \\
\text { A, A }\end{array}$ & $\begin{array}{l}1 \cdot 3 \\
1 \cdot 0 \\
1 \cdot 0 \\
1 \cdot 2 \\
+E\end{array}$ & $\begin{array}{c}10 \cdot 0 \\
12 \cdot 1 \\
10 \cdot 4 \\
11 \cdot 7 \\
\text { A, A }\end{array}$ & $\begin{array}{c}0.8 \\
1.2 \\
0.9 \\
0.9 \\
+E\end{array}$ & $\begin{array}{l}18 \cdot 8 \\
18 \cdot 7 \\
21 \cdot 1 \\
21 \cdot 7 \\
\text { A, A }\end{array}$ & $\begin{array}{r}0.7 \\
1.1 \\
0.8 \\
1.2 \\
+E\end{array}$ & $\begin{array}{r}13 \cdot 1 \\
11 \cdot 2 \\
12 \cdot 8 \\
11 \cdot 4 \\
\text { E, A }\end{array}$ & $\begin{array}{r}0.9 \\
1.2 \\
1.0 \\
0.9 \\
+E\end{array}$ \\
\hline Phosphatidyl choline & $\begin{array}{l}\text { Control } \\
+\mathrm{E} \\
+\mathrm{A} \\
\mathrm{A}+\mathrm{E} \\
P<0.05\end{array}$ & $\begin{array}{l}28 \cdot 1 \\
28 \cdot 1 \\
30 \cdot 1 \\
30 \cdot 0\end{array}$ & $\begin{array}{l}1.8 \\
1.9 \\
2.0 \\
1.7\end{array}$ & $\begin{array}{l}32 \cdot 8 \\
32 \cdot 3 \\
28 \cdot 2 \\
30 \cdot 3\end{array}$ & $\begin{array}{l}1.8 \\
1.6 \\
1.8 \\
1.8\end{array}$ & $\begin{array}{l}11.5 \\
11.5 \\
11.9 \\
11.7\end{array}$ & $\begin{array}{l}0.9 \\
0.8 \\
0.4 \\
0.8\end{array}$ & $\begin{array}{l}19 \cdot 5 \\
19 \cdot 6 \\
23 \cdot 4 \\
20 \cdot 7\end{array}$ & $\begin{array}{l}1 \cdot 6 \\
1 \cdot 3 \\
1 \cdot 4 \\
1 \cdot 8\end{array}$ & $\begin{array}{l}7 \cdot 9 \\
8 \cdot 4 \\
6 \cdot 3 \\
7 \cdot 1\end{array}$ & $\begin{array}{l}1.1 \\
1.4 \\
0.9 \\
1.0\end{array}$ \\
\hline Triglycerides & $\begin{array}{l}\text { Control } \\
+\mathrm{E} \\
+\mathrm{A} \\
\mathrm{A}+\mathrm{E} \\
P<0.05\end{array}$ & $\begin{array}{l}25 \cdot 3 \\
26 \cdot 4 \\
24 \cdot 3 \\
26 \cdot 6\end{array}$ & $\begin{array}{l}1 \cdot 8 \\
1.2 \\
1.5 \\
1.4\end{array}$ & $\begin{array}{l}17 \cdot 2 \\
15 \cdot 6 \\
18 \cdot 3 \\
15 \cdot 4\end{array}$ & $\begin{array}{l}0.8 \\
1.6 \\
1.4 \\
1.6\end{array}$ & $\begin{array}{l}27 \cdot 4 \\
27 \cdot 2 \\
32 \cdot 1 \\
29 \cdot 6\end{array}$ & $\begin{array}{l}1 \cdot 1 \\
1 \cdot 2 \\
1 \cdot 4 \\
1 \cdot 3\end{array}$ & $\begin{array}{l}30 \cdot 0 \\
30 \cdot 5 \\
25 \cdot 3 \\
28 \cdot 2\end{array}$ & $\begin{array}{l}1.6 \\
1.5 \\
1.7 \\
1.6\end{array}$ & & \\
\hline Cholesteryl esters & $\begin{array}{l}\text { Control } \\
+\mathrm{E} \\
+\mathrm{A} \\
\mathrm{A}+\mathrm{E} \\
P<0.05\end{array}$ & $\begin{array}{r}17 \cdot 5 \\
18 \cdot 6 \\
18 \cdot 1 \\
21 \cdot 1 \\
\text { A. }\end{array}$ & $\begin{array}{l}1.4 \\
1.5 \\
1.8 \\
1.6 \\
E\end{array}$ & $\begin{array}{r}9 \cdot 3 \\
9 \cdot 4 \\
11 \cdot 0 \\
20 \cdot 8 \\
\text { A. }\end{array}$ & $\begin{array}{l}0.9 \\
1.0 \\
1.1 \\
1.6 \\
+E\end{array}$ & $\begin{array}{c}33 \cdot 9 \\
34 \cdot 4 \\
37 \cdot 8 \\
26 \cdot 1 \\
\text { A, A }\end{array}$ & $\begin{array}{r}2 \cdot 0 \\
2 \cdot 6 \\
1 \cdot 7 \\
1 \cdot 8 \\
+E\end{array}$ & $\begin{array}{l}26 \cdot 5 \\
26 \cdot 0 \\
26 \cdot 2 \\
23 \cdot 2\end{array}$ & $\begin{array}{l}1.9 \\
1.8 \\
2.1 \\
2.6\end{array}$ & $\begin{array}{c}12 \cdot 7 \\
11 \cdot 5 \\
6 \cdot 8 \\
8 \cdot 7 \\
\text { A, A }\end{array}$ & $\begin{array}{r}1.6 \\
1.0 \\
0.9 \\
1.0 \\
+E\end{array}$ \\
\hline
\end{tabular}

* For details of diets, see p. 410.

Table 5. Fatty acid and cholesterol synthesis from lactate and desaturation of stearic acid by liver homogenates from chicks given the experimental diets*

(Mean values and standard deviations for six chicks calculated per gram fresh tissue. Values were tested by two factor analysis of variance for significance of vitamin $A(A)$, tocopherol (E) and the interaction $(\mathrm{A}+\mathrm{E})$ )

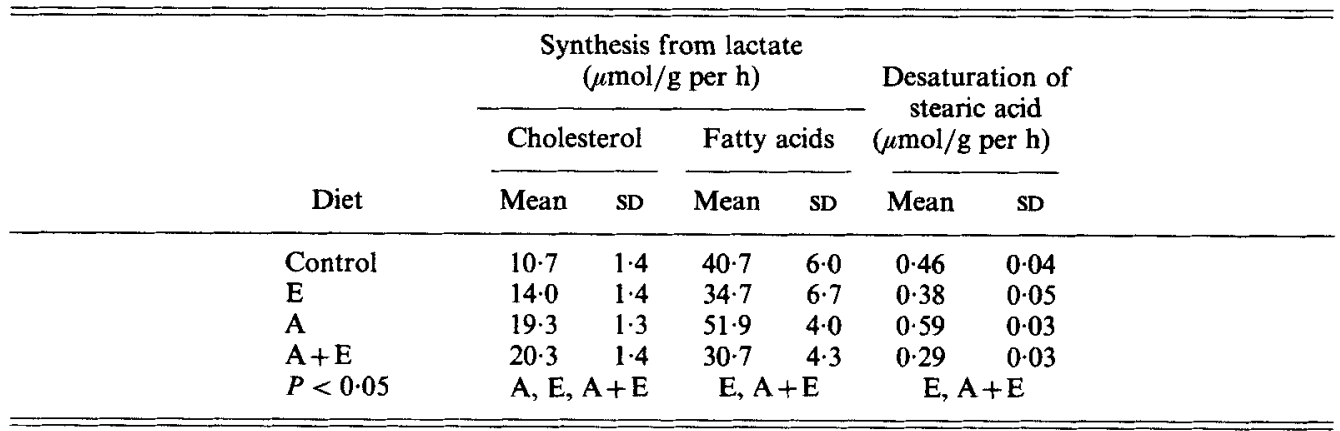

* For details of diets, see p. 410 . 


\section{DISCUSSION}

Feeding high levels of vitamin A or tocopherol increased plasma and liver concentrations. A + E-fed chicks had lower tocopherol levels than E-treated chicks as has been previously described (Sklan \& Donoghue, 1982).

The effect of vitamin A on serum cholesterol and hepatic triglycerides observed in this study confirm previous reports that serum cholesterol was decreased (March \& Biely, 1963; Ram \& Misra, 1978). Some enhancement of fatty acid synthesis was found in vitro in liver homogenates as has been previously reported in the rat (Singh \& Singh, 1978). In addition, changes in $\Delta^{9}$ desaturation due to vitamin A were noted: this is reflected in the fatty acid profiles. In previous studies it was indicated that the increase in hepatic fatty acid synthesis was not accompanied by an increase in transport from the liver (Setty \& Misra, 1975; Singh \& Singh, 1978).

In the present study differences in over-all absorption of fatty acids from the intestine were observed to be due to vitamin A, whereas enterohepatic circulation of fatty acids was enhanced. A similar effect was observed with cholesterol; no differences in excretion through the ileum were found although duodenal secretion was enhanced. In vitro cholesterogenesis from lactate was also enhanced in A-treated chicks, serum levels were depressed and hepatic levels enhanced. In other studies hepatic cholesterogenesis and lipogenesis were depressed on feeding cholesterol or fatty acids respectively (Romsos \& Leveille, 1975; Sklan et al. $1975 a$; Sklan \& Budowski, 1979). However, bile acid production increased with increasing hepatic cholesterol in the chick (Sklan \& Budowski, 1979). It is thus possible that, in response to increasing hepatic concentrations with no corresponding increase in hepatic output to the circulation, the enterohepatic circulation is enhanced by vitamin $A$. This would also be compatible with the reciprocal effects on hepatic and plasma cholesterol.

Feeding chicks high dietary tocopherol, in this study, enhanced liver triglycerides and cholesterol as has been previously found in the rat (Yang \& Desai, 1977; Porta et al. 1980). In addition, the enterohepatic circulation of cholesterol was enhanced and cholesterol synthesis was also increased and fatty acid synthesis depressed. Bile acid secretion to the duodenum was also enhanced, probably due to the increase in hepatic cholesterol levels and enhanced cholesterol $7 \alpha$-hydroxylase. This confirms the hypothesis of Kritchevsky et al. (1980) in the rat that feeding tocopherol or other anti-oxidants affects hepatic cholesterol metabolism.

Feeding high levels of both vitamin A and tocopherol together further increased hepatic cholesterol levels beyond that observed in either A-treated or E-treated chicks, although other factors were not influenced in this manner.

It is concluded that both vitamins $A$ and $E$ affect the hepatic synthesis and oxidation of cholesterol and influence fatty acid metabolism in the chick.

This study was supported by a grant from the Wolfson Foundation, The Hebrew University. Skilled technical assistance was by Mrs O. Kedar.

\section{REFERENCES}

Bring, S. V., Ricard, C. A. \& Wahringer, M. V. (1965). Journal of Nutrition 85, $400-406$.

Folch, J., Lees, M. \& Stanley, G. H. S. (1957). Journal of Biological Chemistry $226,497$.

Harrill, I., Minarik, G. \& Gilford, E. D. (1965). Journal of Nutrition 87, 424-428.

Kritchevsky, D., Nitzsche, C., Czarnecki, S. \& Story, J. A. (1980). Nutrition Reports International 22, $339-342$.

Lakshmanan, M. R., Phillips, W. E. J. \& Brien, R. L. (1969). British Journal of Nutrition 23, 25-30.

Mallia, A. K., Smith, J. E. \& Goodman, D. S. (1975). Journal of Lipid Research 16, 180-188.

March, B. E. \& Biely, J. (1963). Journal of Nutrition 79, 474-478.

Porta, E. A., Joun, N. S. \& Nitta, R. T. (1980). Mechanisms of Ageing and Development 13, 1-29.

Porta, E. A., Keopuhiwa, L., Joun, N. S. \& Nitta, R. T. (1981). Mechanisms of Ageing and Development 15, $297-335$. 
Prodouz, K. N. \& Naveri, R. M. (1975). Nutrition Reports International 11, 17-28.

Ram, G. C. \& Misra, U. K. (1978). World Review of Nutrition and Dietetics 31, 77-82.

Riesenfeld, G., Wals, P. A., Golden, S. \& Katz, J. (1981). Journal of Biological Chemistry 256, 9973-9980.

Romsos, D. R. \& Leveille, G. (1975). In Modification of Lipid Metabolism, pp. 127-138 [E. G. Perkins and L. A. Witting, editors]. New York: Academic Press.

Setty, O. H. \& Misra, U. K. (1975). International Journal of Vitamin and Nutrition Research 45, $107-112$.

Setty, O. H. \& Misra, U. K. (1981). Acta Vitaminologica Enzymologica 3, 70-77.

Singer, E. J. \& Fitschen, W. H. (1961). Analytical Biochemistry 2, 292-302.

Singh, M. \& Singh, V. N. (1978). American Journal of Physiology 234, E511-E514.

Singh, V. N., Singh, M. \& Venkitasubramanian, T. A. (1969). Journal of Lipid Research 10, 395-401.

Sklan, D. (1983). British Journal of Nutrition 50, 401-407.

Sklan, D., Ascarelli, I. \& Budowski, P. (1974). Poultry Science 53, 1239-1242.

Sklan, D. \& Budowski, P. (1979). Lipids 14, 386-390.

Sklan, D. \& Donoghue, S. (1982). Journal of Nutrition 112, 759-765.

Sklan, D., Dubrov, D., Eisner, U. \& Hurwitz, S. (1975a). Journal of Nutrition 105, 1549-1552.

Sklan, D., Hurwitz, S., Ascarelli, I. \& Budowski, P. (1975b). Journal of Nutrition 105, 57-63.

Solomon, L. W. \& Erdman, J. W. (1980). Lipids 15, 157-162.

Wahle, K. W. J. (1974). Comparative Biochemistry and Physiology 48B, 87-105.

Yang, N. Y. J. \& Desai, I. D. (1977). Journal of Nutrition 107, 1418-1426. 